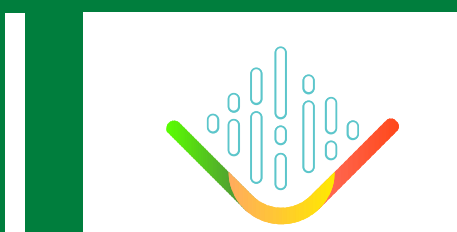

REVISTA ELETRÔNICA CIENTÍFICA DA UERGS
Custo financeiro com o desperdício de vacinas na região metropolitana de Porto Alegre, Rio Grande do Sul, Brasil

\title{
Scheila Mai
}

Universidade Federal do Rio Grande do Sul (UFRGS) e Universidade do Vale do Rio dos Sinos (UNISINOS).

E-mail: scheilamai@unisinos.br, http://lattes.cnpq.br/I423 I5 I 4873294 I3

Roger dos Santos Rosa

Universidade Federal do Rio Grande do Sul (UFRGS).

E-mail: roger.rosa@ufrgs.br, http://lattes.cnpq.br/660 I I04II 7405392

\section{Fábio Herrmann}

Pontifícia Universidade Católica do Rio Grande do Sul, Escola de Medicina (PUC-RS).

fabioherrmannfh@gmail.com, http://lattes.cnpq.br/93605089324975।3

Adriane da Silva Carvalho

Universidade Federal do Rio Grande do Sul (UFRGS).

adrianedasc@hotmail.com, http://lattes.cnpq.br/865380I35I505877

Vania Celina Dezoti Micheletti

Universidade do Vale do Rio dos Sinos (UNISINOS).

vaniadm@unisinos.br, http://lattes.cnpq.br/I66/437592439970

Ronaldo Bordin

Universidade Federal do Rio Grande do Sul (UFRGS).

ronaldo.bordin@ufrgs.br, http://lattes.cnpq.br/69099||499|78658

ISSN 2448-0479 Submetido em: 16 ago. 2020. Aceito: 2 I jan. 202 I. DOI: http://dx.doi.org/10.21674/2448-0479.7I.131-|4I

\section{Resumo}

O Programa Nacional de Imunização do Brasil é referência internacional, devido à grande oferta de imunobiológicos para população, destinado as diferentes faixas etárias de forma pública e gratuita. Com o importante aumento de investimentos públicos nessa área, esse estudo tem como objetivo estimar as taxas de perda e utilização de doses de vacinas de frascos multidose e monodose, na Região Metropolitana de Porto Alegre, Rio Grande do Sul, no período de 2015 a 2017. A metodologia desse estudo descritivo foi realizada a partir de dados secundários do Sistema de Informação do Programa Nacional de Imunizações (SI-PNI) e Sistema de Informação de Insumos Estratégicos (SIES). Foram estudadas nove vacinas, sendo que o desperdício médio foi de 962.013 doses que representaram aproximadamente $R \$ 3,5$ milhões. Para as vacinas de apresentação multidose, o desperdício médio ( $R$ \$I.079.143) foi quatro vezes maior que o aceitável $(R \$ 269.785)$. Já para vacinas de frascos monodose ( $R \$$ I.298.159) foi vinte vezes maior ( $R \$ 64.908)$. Deste modo, os custos com o desperdício de doses de vacinas $(44,7 \%)$ têm onerado recursos públicos que poderiam subsidiar investimentos em melhorias do sistema de saúde.

Palavras Chaves: Vacina. Desperdício. Economia da saúde. Gestão pública. 


\section{Financial cost of vaccine waste in the metropolitan region of Porto Alegre, Rio Grande do Sul, Brazil}

The National Immunization Program of Brazil is an international reference, due to the large offer of immunobiologicals for the population, intended for different age groups in a public and free. With the significant increase in public investments in this area, this study aims to estimate the rates of loss and use of doses of vaccines from multidose and single-dose vials in the Metropolitan Region of Porto Alegre, Rio Grande do Sul, from 2015 to 2017. The methodology of this descriptive study was carried out using secondary data from Information System of the National Immunization Program and Strategic Inputs Information System Nine vaccines were studied, with an average waste of 962,013 doses, which represents approximately $R \$ 3.5$ million, that is, more than US\$700.00. For multidose vaccines, the average waste ( $R \$ 1,079,143)$ was four times greater than acceptable ( $R \$ 269,785)$. For single-dose vaccines $(R \$ 1,298,159)$ it was twenty times higher ( $R \$ 64,908)$. Thus, the costs of wasting vaccine doses $44.7 \%$ have been a burden on public resources that can invest in improvements in the health system.

Keywords: Vaccine. Waste. Health economics. Public administration.

\section{Resumen}

\section{Costo financiero del desperdicio de vacunas en la región metropolitana de Porto Alegre, Rio Grande do Sul, Brasil}

El Programa Nacional de Inmunización de Brasil es una referencia internacional, debido a la gran oferta de inmunobiológicos para la población, destinados a diferentes grupos de edad de forma pública y gratuita. Con el aumento significativo de las inversiones públicas en esta área, ese estudio tiene como objetivo estimar las tasas de pérdida y uso de dosis de vacunas de viales multidosis y monodosis en la Región Metropolitana de Porto Alegre, Rio Grande do Sul, en el periodo de 2015 a 2017. La metodología de este estudio descriptivo fue realizada por medio de datos secundarios del Sistema de Información del Programa Nacional de Inmunizaciones (SI-PNI) y del Sistema de Información de Insumos Estratégicos (SIES). Fueron estudiadas nueve vacunas, con un desperdicio promedio de 962.013 dosis, lo que representaron aproximadamente $R \$ 3,5$ millones. Para las vacunas multidosis, el desperdicio promedio ( $\mathrm{R} \$ \mathrm{I}$.079.143) fue cuatro veces mayor de lo aceptable ( $R$ \$ 269.785). Para las vacunas monodosis ( $R$ \$ I.298.159) fue veinte veces mayor ( $\$$ \$64.908). De este modo, los costos con el desperdicio de dosis de vacunas $(44,7 \%)$ han sido costoso para los recursos públicos que podrían invertir en mejoras en el sistema de salud.

Palabras clave: Vacuna. Residuos. Economía de la Salud. Gestión pública.

\section{Introdução}

A importância da vacinação pode ser percebida ao se analisar o investimento crescente realizado nos programas de imunizações. Na década de 1980, a despesa média anual com vacinas, nos países em desenvolvimento, foi de aproximadamente US\$3,50 a US\$5,00 por nascido vivo. Em 2000, elevou-se para cerca de US\$ 6,00, em 2010 para US\$ 18,00 , e de 2011 a 2015 , após a incorporação de novas vacinas, para US\$ 24,90 (UNICEF, 2010). A Organização Mundial de Saúde (OMS) estimou de 2016 a 2020, um custo em vacinas de US\$ 32,60 por nascido vivo (UNICEF, 2010; LYDON et al., 2014). A previsão dos custos em atividades de imunizações da vacina, entre os anos 20 I I-2020, para subsidiar os países de baixa e média renda na ampliação da cobertura e introdução de novas vacinas, foi de US\$ 57,50 bilhões (GANDHI et al., 20I3).

No Brasil, o Programa Nacional de Imunização (PNI) vem aumentando seus investimentos. Em menos de uma década, passou de um orçamento de $R \$ 200$ milhões para $R \$ 825$ milhões em 2009 (BRASIL, 2003; BRASIL, 20I3). De 2004 a 20I5, o custo foi de $R \$ 15.473 .789 .880$, totalizando 2.910.669. I I 4 doses adquiridas pelo programa (MOURA, 2016). Em um país de dimensões continentais como o Brasil, com mais de 200 milhões de habitantes, torna-se um desafio para o PNI organizar o controle, a eliminação e/ou a erradicação de doenças imunopreveníveis. Ressalta-se que o PNI compreende uma das intervenções mais impactantes em saúde pública (BRASIL, 2003; BRASIL, 20I3). Seu crescimento é reconhecido internacionalmente, sendo 
considerado um dos mais completos, dentre os países em desenvolvimento, e pioneiro na introdução de novas vacinas (HOMMA et al., 20I I).

Quando há introdução de novas vacinas (geralmente mais caras), há a preocupação com o aumento do desperdício (HEATON et al., 2017). As vacinas introduzidas mais recentemente tendem a ser mais eficazes, mas também mais caras - até cinco vezes mais (GAVI, 20l4). Estima-se que até 2020, as vacinas mais recentes representam mais de $40 \%$ dos custos totais de vacinas (GANDHI et al., 20I3). Vacinas novas e mais complexas trarão novas exigências financeiras e os países deverão estar preparados para tomada de decisão que compete aos recursos alocados de forma mais eficiente (WORLD HEALTH ORGANIZATION, 20I3).

É necessário o acompanhamento do desperdício de vacinas, pois pode onerar o orçamento público e desperdiçar recursos importantes. Nesse sentido é importante que estudos de custo-efetividade sejam realizados para fortalecer o PNI, poder quantificar de forma precisa e consistente o desperdício de vacinas poderá auxiliar na tomada de decisões com bases técnicas para redução de gastos e obtenção de maior economia de custos.(GUICHARD et al., 20 I0; PEREIRA, 20 3; ). Dada a importância do tema, este estudo tem como objetivo estimar o custo financeiro do desperdício de vacinas na Região Metropolitana de Porto Alegre, Rio Grande do Sul, no triênio de 20I5-20I7.

\section{Material e Métodos}

Desenho do estudo

Trata-se de um estudo descritivo com dados secundários extraídos do Sistema de Informação do Programa Nacional de Imunizações (SI-PNI) e do Sistema de Informação Insumos Estratégicos em Saúde (SIES). No triênio 2015-2017. Foram considerados 34 municípios da Região Metropolitana de Porto Alegre, área mais densamente povoada do estado do Rio Grande do Sul, com mais de 4 milhões de habitantes (37,7\% da população total do Estado) (RIO GRANDE DO SUL- RS, 20I8).

\section{Coleta e extração de dados}

Para a coleta de dados, realizada em março de 20I8, foi elaborada uma planilha no software Microsoft Excel ${ }^{\circledR}$ versão 2010 , com as informações dos dois sistemas, SI-PNI e SIES. O banco de dados foi organizado em diferentes abas, cada uma correspondendo a um dos II imunobiológicos específicos: (I) vacina do bacilo de Calmette-Guérin (BCG); (II) vacina contra hepatite B (recombinante); (III) vacina contra febre amarela (atenuada); (IV) vacina adsorvida contra difteria e tétano/adulto(dT); (V) vacina adsorvida contra difteria, tétano e pertussis (DTP); (VI) vacina contra influenza tetravalente (fragmentada, inativada); (VII) vacina adsorvida contra difteria, tétano, pertússis, hepatite B (recombinante) e Haemophilus influenzae B (conjugada); (VIII) vacina adsorvida contra hepatite A (inativada); (IX) vacina contra sarampo, caxumba, rubéola e varicela (atenuada); $(\mathrm{X})$ vacina adsorvida contra difteria, tétano e pertússis (acelular)/adulto (dTpa); e (XI) vacina contra sarampo, caxumba e rubéola (atenuada).

As informações coletadas correspondentes a cada imunobiológico específico abrangeram as seguintes variáveis: (I) município da Região Metropolitana, (II) ano de referência, (III) doses no início do período, (IV) valor das doses no início do período, (V) doses recebidas no período, (VI) valor das doses recebidas no período, (VII) saídas de doses no período, (VIII) valor das doses saídas no período, (IX) estoque final de doses no período, $(\mathrm{X})$ valor do estoque final de doses no período e (XI) doses aplicadas.

\section{Tratamento dos dados}

Para análise, foram consolidados em um arquivo principal I 2.342 registros correspondentes a II variáveis para cada um dos II imunobiológico de 34 municípios, por um período de 3 anos. Destes, 2.244 (I8,2\%) registros, referentes às vacinas influenza e dTpa, foram excluídos da análise por inconsistência de informações, isto é, cálculo de desperdício negativo, em mais de $25 \%$ dos dados. Restaram, assim, 9 vacinas em estudo. Os softwares para tratamento dos dados foram Microsoft Excel ${ }^{\circledR}$ versão 2010 e Statistical Package for the Social Sciences (SPSS $\left.{ }^{\circledR}\right)$ versão 20.

Para o cálculo da taxa de utilização e da taxa de desperdício, foram utilizadas as fórmulas sugeridas pela OMS (WHO, 2005), adaptadas por Mai et al. (2019): 


$$
\begin{aligned}
& \text { Taxa de utilização }(T U) \text { : } \\
& \text { TU: }\{A /[(B+C)-D]\} * 00
\end{aligned}
$$

Legenda: $A: n^{\circ}$ de doses administradas; $B: n^{\circ}$ de doses utilizáveis no início do período; $C: n^{\circ}$ de doses utilizáveis recebidas durante o período; $\mathrm{D}: \mathrm{n}^{\circ}$ de doses utilizáveis em estoque no final do período

$$
\begin{gathered}
\text { Taxa de perdas/desperdício (TP): } \\
\text { TP: }\{[(A+B)-(C+D)] /[(A+B)-C]\} * 100
\end{gathered}
$$

Legenda: $A: n^{\circ}$ de doses utilizáveis no início do período; $B: n^{\circ}$ de doses utilizáveis recebidas durante o período; $C: \mathrm{n}^{\circ}$ de doses utilizáveis em estoque no final do período; $\mathrm{D}: \mathrm{n}^{\circ}$ de doses administradas.

Para o cálculo do custo da dose, a coleta de dados no SIES partiu da identificação do valor unitário da vacina a cada aquisição. Os relatórios do SIES registram o valor total da entrada do lote, por vacina, relativo à quantidade de doses a cada aquisição. Assim, foi necessário realizar uma média de valor anual, que será apresentada posteriormente nos resultados.

Ressalta-se que os custos apresentados neste estudo são valores restritos à dose da vacina, não incluindo os custos com a cadeia de frio, os recursos humanos, o transporte e o descarte dos insumos. Ainda, destaca-se que, no Brasil, cabe aos Estados e Distrito Federal a solicitação mensal de imunobiológicos, e, diante dos pedidos, cabe à Coordenação Geral do PNI a análise minuciosa, considerando critérios como a média histórica de distribuição daquele mês nos anos anteriores, quantitativo disponível em estoque, validade de imunobiológicos, situações de surtos e/ou emergências em saúde bem como cronograma de entrega dos imunobiológicos pelos laboratórios produtores. Após essa análise, a autorização ou não do pedido ocorre no SIES (BRASIL, 20I4).

\section{Aspectos éticos}

Quanto aos aspectos éticos, o estudo baseou-se em relatórios gerenciais de controle de estoques, gerados a partir de dados secundários, sem a utilização de informações que permitissem a identificação de indivíduos em ambos os sistemas de informação. Os dados brutos utilizados foram em sua maioria de domínio público, disponibilizados pelo Departamento de Informática do Sistema Único de Saúde (DataSUS) em meio eletrônico, e os demais dados necessários foram disponibilizados mediante solicitação de relatórios específicos em níveis gerenciais das áreas de Vigilância em Saúde da Secretaria Estadual de Saúde. O estudo atende as Resoluções n 466/2012 e n 510/2016 do Conselho Nacional de Saúde (CNS).

\section{Resultados}

Para a Região Metropolitana de Porto Alegre/RS, estimou-se um desperdício de 2.886 .039 doses de vacinas, as quais representaram aproximadamente $\mathrm{R} \$ 10,5$ milhões no período $20 \mathrm{I} 5-2017$ (Tabela I). $O$ valor médio por dose, para cada vacina no respectivo ano, foi estimado a partir do valor e da quantidade total das doses que foram recebidas detalhados na Tabela $\mathrm{I}$.

Tabela I- Doses recebidas ( $n$ e R\$), valor médio por dose (R\$) e doses desperdiçadas ( $n$ e R\$), por tipo de vacina, Região Metropolitana de Porto Alegre - RS, 20I5-20I7.

\begin{tabular}{ccccccc}
\hline Vacina & Ano & $\begin{array}{c}\text { \#Doses } \\
\text { recebidas } \\
(\mathbf{A})\end{array}$ & $\begin{array}{c}\text { \#Doses } \\
\text { recebidas } \mathbf{R} \$ \\
\mathbf{( B )}\end{array}$ & $\begin{array}{c}\text { *Valor médio } \\
\text { por dose } \mathbf{R} \$ \\
\mathbf{( B / A )}\end{array}$ & $\begin{array}{c}\text { *Doses } \\
\text { desperdiçadas } \\
\text { (C) }\end{array}$ & $\begin{array}{c}\text { *Doses } \\
\text { desperdiçadas } \\
\mathbf{R} \$ \\
\text { (C*B/A) }\end{array}$ \\
\hline BCG & 2016 & 149.850 & 221.013 & 1,47 & 107.825 & 159.031 \\
BCG & 2017 & 113.180 & 166.630 & 1,47 & 63.473 & 93.448 \\
dT & 2015 & 217.730 & 66.858 & 0,31 & 109.785 & 33.711 \\
dT & 2016 & 210.120 & 101.071 & 0,48 & 72.645 & 34.943 \\
dT & 2017 & 220.010 & 102.806 & 0,47 & 65.339 & 30.531
\end{tabular}




\begin{tabular}{|c|c|c|c|c|c|c|}
\hline Vacina & Ano & $\begin{array}{l}\text { \#Doses } \\
\text { recebidas } \\
\text { (A) }\end{array}$ & $\begin{array}{c}\text { \#Doses } \\
\text { recebidas R\$ } \\
\text { (B) }\end{array}$ & $\begin{array}{c}\text { *Valor médio } \\
\text { por dose R\$ } \\
\text { (B/A) }\end{array}$ & $\begin{array}{c}\text { *Doses } \\
\text { desperdiçadas } \\
\text { (C) }\end{array}$ & $\begin{array}{c}\text { *Doses } \\
\text { desperdiçadas } \\
\mathbf{R} \$ \\
\text { (C*B/A) }\end{array}$ \\
\hline DTP & 2015 & 198.370 & 118.906 & 0,60 & 113.236 & 67.875 \\
\hline DTP & 2016 & 76.510 & 55.926 & 0,73 & 16.555 & 12.101 \\
\hline DTP & 2017 & 118.660 & 108.164 & 0,91 & 39.545 & 36.047 \\
\hline FA & 2015 & 405.850 & 722.884 & $\mathrm{I}, 78$ & 309.892 & 551.967 \\
\hline FA & 2016 & 300.087 & 761.356 & 2,54 & 176.388 & 447.517 \\
\hline FA & 2017 & 173.212 & 447.080 & 2,58 & 53.505 & 138.102 \\
\hline Hepatite A & 2015 & 78.986 & 1.363 .410 & 17,26 & 25.799 & 445.327 \\
\hline Hepatite A & 2016 & 39.169 & 1.032 .424 & 26,36 & 9.093 & 239.675 \\
\hline Hepatite A & 2017 & 57.597 & 1.999 .887 & 34,72 & 12.990 & 451.039 \\
\hline Hepatite B & 2015 & 497.530 & 753.866 & 1,52 & 353.923 & 536.270 \\
\hline Hepatite B & 2016 & 319.080 & 476.162 & $\mathrm{I}, 49$ & 184.223 & 274.915 \\
\hline Hepatite B & 2017 & 194.340 & 174.057 & 0,90 & 77.970 & 69.832 \\
\hline Pentavalente & 2015 & 244.157 & 1.527.318 & 6,26 & 98.810 & 618.103 \\
\hline Pentavalente & 2016 & 172.926 & 1.076 .623 & 6,23 & 41.278 & 256.993 \\
\hline Pentavalente & 2017 & I 28.872 & 927.615 & 7,20 & 16.289 & 117.247 \\
\hline Tetra viral & 2015 & 67.525 & 2.087.27I & 30,91 & 32.450 & 1.003 .065 \\
\hline Tetra viral & 2016 & 49.237 & 1.719 .700 & 34,93 & 9.460 & 330.409 \\
\hline Tetra viral & 2017 & 45.252 & I.805.646 & 39,90 & 10.842 & 432.617 \\
\hline Tríplice viral & 2015 & 408.308 & I.872.746 & 4,59 & 334.729 & 1.535 .268 \\
\hline Tríplice viral & 2016 & $277.74 I$ & 1.264 .618 & 4,55 & 180.950 & 823.906 \\
\hline Tríplice viral & 2017 & 193.684 & 1.562 .870 & 8,07 & 122.729 & 990.322 \\
\hline Total & Triênio & 5.264 .973 & 23.453 .074 & & 2.886 .039 & 10.481 .407 \\
\hline Total & Média anual & I.754.99| & 7.817 .692 & & 962.013 & 3.493 .802 \\
\hline
\end{tabular}

Fonte: \# Dados secundários do Sistema de Informação de Insumos Estratégicos em Saúde (SIES). *Dados estimados pelos autores (20I8).

Conforme a tabela 2, na Região Metropolitana de Porto Alegre/RS, o desperdício atingiu em média 962.013 doses e $R \$ 3.493 .802$ anualmente. A vacina com maior média anual de doses $(2 / 2.803)$ e valores (R\$ I.I 16.499) desperdiçados foi a Tríplice Viral, seguida da Tetra Viral em valores ( $R$ \$ 588.679). A vacina de menor desperdício médio foi a dT ( $\mathrm{R} \$ 33.062$ ), embora não seja a com menor desperdício em doses (82.590), mas com o menor valor médio da dose $(\mathrm{R} \$ 0,40)$.

Tabela 2 - Doses anuais ( $n$ e R\$) aplicadas e desperdiçadas, por tipo de vacina, Região Metropolitana de Porto Alegre - RS, 2015-2017.

\begin{tabular}{ccccc} 
Vacina & $\begin{array}{c}\text { \#Doses aplicadas } \\
(\mathbf{n})\end{array}$ & $\begin{array}{c}\text { *Doses aplicadas } \\
\mathbf{( R \mathbf { 5 } )}\end{array}$ & $\begin{array}{c}\text { \#Doses desperdiçadas } \\
(\mathbf{n})\end{array}$ & $\begin{array}{c}\text { *Doses desperdiçadas } \\
\text { (R\$) }\end{array}$ \\
\hline BCG & 53.245 & 108.928 & 139.205 & 334.537 \\
dT & 135.540 & 57.380 & 82.590 & 33.062 \\
DTP & 72.871 & 53.820 & 56.445 & 38.674 \\
Febre amarela & 110.329 & 257.973 & 179.928 & 379.195 \\
Hepatite A & 42.242 & 1.073 .416 & 15.961 & 378.680
\end{tabular}




\begin{tabular}{ccccc} 
Vacina & $\begin{array}{c}\text { \#Doses aplicadas } \\
(\mathbf{n})\end{array}$ & $\begin{array}{c}\text { *Doses aplicadas } \\
\mathbf{( R \mathbf { ) }}\end{array}$ & $\begin{array}{c}\text { \#Doses desperdiçadas } \\
\mathbf{( n )}\end{array}$ & $\begin{array}{c}\text { *Doses desperdiçadas } \\
\mathbf{( R \mathbf { ) } )}\end{array}$ \\
\hline Hepatite B & 133.885 & 174.690 & 205.372 & 293.672 \\
Pentavalente & 129.948 & 847.204 & 52.126 & 330.781 \\
Tetra viral & 35.876 & $1.261 .759,3$ & 17.584 & 588.697 \\
Tríplice viral & 85.135 & $490.300,5$ & 212.803 & 1.116 .499 \\
\hline TOTAL & 799.071 & 4.325 .472 & 962.013 & 3.493 .802
\end{tabular}

Fonte: \# Dados secundários do Sistema de Informação de Insumos Estratégicos em Saúde (SIES). *Dados estimados pelos autores (2018).

Entre as vacinas com maiores custos, a BCG obteve uma média anual de $R \$ 443.465$, sendo $R \$ 334.537$ $(75,4 \%)$ desperdiçados, enquanto $\mathrm{R} \$ 108.928(24,6 \%)$ corresponderam às vacinas aplicadas. Para a Hepatite $B$, o custo médio anual foi de $R \$ 468.362$, dos quais 293.672 (62,7\%) foram desperdiçados. A Febre Amarela teve um custo médio anual de $R \$ 637.168$, dos quais $R \$ 379.195(59,5 \%)$ desperdiçados. Já as vacinas com menores custos médios anuais foram a dT (R\$90.442) e a DTP ( $R$ \$92.494) cujos desperdícios representaram $\mathrm{R} \$ 33.062(36,5 \%)$ e $\mathrm{R} \$ 38.674$ (4I,8\%), respectivamente.

Para as vacinas monodose, a Tetra viral apresentou o maior custo médio anual ( $\mathrm{R} \$$ I.850.456) e desperdício médio de $R \$ 588.697$ ( 31 , 8\%). Foi seguida pela Hepatite $A$, com um custo médio anual de $R \$ 1.452 .096$, dos quais $\mathrm{R} \$ 378.680$ (26\%) desperdiçados. A redução de desperdícios poderá garantir, entre outros, a estabilidade financeira dos programas de imunizações (MOFRAD et al., 2016). Por isso, foi estimado, na tabela 3 , o quanto seria esse desperdício se os mesmos estivessem dentro do limite aceitável pela OMS que é de no máximo 25\% para vacinas multidose e 5\% para vacinas monodose (WHO, 2005; MAl et al., 2019).

Tabela 3 - Desperdício de vacinas (n e R\$) versus desperdício aceitável pela OMS (n e R\$), na Região Metropolitana de Porto Alegre - RS, 2015-2017.

\begin{tabular}{|c|c|c|c|c|}
\hline Vacina\# & $\begin{array}{c}\text { Doses } \\
\text { desperdiçadas } \\
\text { (n) }\end{array}$ & $\begin{array}{c}\text { Doses } \\
\text { desperdiçadas } \\
(\mathbf{R} \$)\end{array}$ & $\begin{array}{c}\text { Doses } \\
\text { desperdiçadas } \\
\text { aceitáveis *(n) }\end{array}$ & $\begin{array}{c}\text { Doses } \\
\text { Desperdiçadas } \\
\text { aceitáveis } \\
*(\mathbf{R} \$)\end{array}$ \\
\hline \multicolumn{5}{|l|}{ Multidose } \\
\hline BCG & 139.205 & 334.537 & 34.801 & 83.634 \\
\hline $\mathrm{dT}$ & 82.590 & 33.062 & 20.648 & 8.265 \\
\hline DTP & 56.445 & 38.674 & $|4|||$. & 9.668 \\
\hline Febre amarela & 179.928 & 379.195 & 44.982 & 94.798 \\
\hline Hepatite B & 205.372 & 293.672 & 51.343 & 73.418 \\
\hline Total multidose & 663.540 & I.079.143 & 165.885 & 269.785 \\
\hline \multicolumn{5}{|l|}{ Monodose } \\
\hline Hepatite A & 15.961 & 378.680 & 798 & 18.934 \\
\hline Pentavalente & 52.126 & 330.781 & 2.606 & 16.539 \\
\hline Tetra viral & 17.584 & 588.697 & 879 & 29.434 \\
\hline Total monodose & 85.670 & I.298.159 & 4.284 & 64.908 \\
\hline Total & 749.210 & 2.377 .303 & 170.169 & 334.693 \\
\hline
\end{tabular}

Fonte: Autores (2018) \# Excluída a vacina tríplice viral devido à apresentação em ambos os formatos.

*Valores estimados segundo os limites aceitáveis pela OMS para desperdício de doses (máximo de $25 \%$ para vacinas multidoses e $5 \%$ para vacinas monodose)

Anualmente, o desperdício em doses de vacinas representou, em média, sete vezes mais ( $R$ \$2.377.303) em relação ao parâmetro aceitável da OMS (R\$334.693). Observa-se que para vacinas de apresentação mul- 
tidose o desperdício médio foi de $\mathrm{R} \$ \mathbf{1} .079 .143$, quando o aceitável seria de $\mathrm{R} \$ 269.785$. Já para as vacinas de frascos monodose, o valor foi de $R \$ 1.298$. I59, quando o aceitável seria de $R \$ 64.908$.

Inobstante, o desperdício médio de doses de vacinas monodose foi de II,4\% (85.67I doses), enquanto para as vacinas multidoses atingiu 88,5\% (663.540 doses). Excluiu-se a Tríplice viral da análise por sua apresentação dar-se em ambos os formatos, o que impossibilita a distinção do valor correspondente à monodose e à multidose.

A vacina de apresentação multidose com maior desperdício médio em doses foi a Hepatite B (205.372 doses). Entretanto, a vacina com maior percentual de desperdício financeiro foi a Febre Amarela, com $\mathrm{R} \$$ 379.195 (35, I\%) do total. Já entre as vacinas de apresentação monodose, aquela com maior desperdício médio em doses foi a Pentavalente (52.126 doses). Contudo, ao se considerar o maior desperdício em custos, destaca-se a Tetra viral com $\mathrm{R} \$ 588.697,42(45,3 \%)$.

\section{Discussão}

Neste estudo, foram apresentados os resultados dos custos financeiros relacionados ao desperdício de vacinas na Região Metropolitana de Porto Alegre - RS, de 2015 a 2017. Cerca de R\$ 10,5 milhões foram desperdiçados em doses não utilizadas no triênio. Nos Estados Unidos da América (EUA), um estudo estimou a perda anual em desperdício no setor público nacional referente a vacinas em US\$ 6-3I milhões (SETIA et al., 2002). Este trabalho estimou uma média anual de quase $R \$ 3,5$ milhões, apenas em custos do desperdício de algumas vacinas (Tabela I), disponíveis no setor público para uma população que representa menos de $2 \%$ do total do território nacional. Assim, acredita-se que uma análise nacional os valores relacionados aos desperdícios seriam ainda maiores do que os apresentados no estudo dos EUA.

No Brasil, um estudo realizado em Juiz de Fora (Minas Gerais) identificou $R \$ 49.633,64$ de custo total anual em desperdícios com duas vacinas a Rotavírus e a Tríplice Viral, no ano de 20I3. (DIAS, 2016). Outro estudo brasileiro, em um município da região metropolitana de Curitiba,evidenciou uma perda anual em torno de R\$ I milhão em desperdícios de vacinas (PEREIRA et al., 2013). . A Aliança Global para Vacinas e Imunizações (GAVI) tem apontado para uma taxa esperada de no máximo $25 \%$ de desperdício para vacinas de multidoses. (GAVI, 20I4). Já para vacinas em dose única ou duas doses, o desperdício poderia ser de no máximo $5 \%$. A OMS considera que o desperdício real possa ser superior a $50 \%$ em todo o mundo (WHO, 2005)Os dados do presente estudo revelam que o desperdício financeiro foi maior que o aceitável pela OMS, representando uma média anual sete vezes maior ( $R$ \$ 2.377.303) do que o limite aceitável pelo parâmetro OMS (R\$ 334.693). Para as vacinas de apresentação multidose, o desperdício anual médio (45,3\%) foi quatro vezes maior ( $R \$$ I.079. I43) do que o aceitável ( $R$ \$269.785). Já para as vacinas de frascos monodose $(54,7 \%)$, foi vinte vezes maior ( $R \$$ I.298.159) do que o aceitável (R\$ 64.908).

O PNI, somente no cenário do estudo, poderia ter uma economia anual de pelo menos $\mathrm{R} \$ 2,3$ milhões, já considerando as perdas "aceitáveis". Ressalta-se que não foi incluída a totalidade dos imunobiológicos disponíveis no calendário vacinal para este resultado, o qual foi obtido examinando apenas 8 das 17 vacinas. Por exemplo, a vacina Tríplice Viral que representou o maior valor médio anual de desperdício R \$ I.I I6.499 (32\%) não foi inclusa na análise de custos, pela impossibilidade de inferir o quantitativo de desperdício de doses referente ao frasco monodose ou multidose. Portanto, estima-se que esses valores, no cenário de estudo, sejam substancialmente mais expressivos ao considerar a totalidade das vacinas.

Para este estudo, o desperdício representou $55 \%$ do total das doses e $44,7 \%$ do total dos custosOs valores em desperdício de vacinas representaram quase a metade custos empregados em doses de vacinas para região do estudo. . Porém, outra preocupação com o desperdício de vacina é na medida em que ocorre o aumento de preço da dose. (WHO, 20I4). O estudo revela que houve intensa variação de preço unitário da dose da mesma vacina. A vacina Hepatite $A$ foi a que apresentou a maior variação ( $R \$ 17,20$ a $R \$ 34,70)$. Em contrapartida, a dT foi a de menor variação ( $R \$ 0,31$ a $R \$ 0,47)$. A vacina Tetra viral foi o imunobiológico com maior custo unitário por dose ( $R \$ 30,90$ a $R \$ 39,90)$. Além disso, ao se incorporar novas vacinas no calendário de rotina, os custos financeiros elevam-se, pois, na maioria das vezes, vacinas novas são mais caras (GUICHARD et al., 20 I0; SETIA et al., 2002). Das vacinas analisadas, as duas últimas a serem incorporadas no calendário vacinal foram a Hepatite $A$ e a Tetra Viral, as quais geraram altos valores médios anuais em desperdícios. Para a Tetra Viral, o valor médio anual foi de $R \$ 588.697$ (31,8\%), enquan- 
to para a Hepatite A foi de $\mathrm{R} \$ 378.680$ (26, I\%). Somente esses dois imunobiológicos representaram em valores quase $30 \%$ da média anual desperdiçada.

O valor médio unitário da dose impacta nos resultados em termos financeiros. A maior média anual de desperdício, em reais, correspondeu a vacina Tríplice Viral com R\$ I. I I6.499 (3I,7\%) que apresentou desperdício de $68,8 \%$ das doses. Entretanto, a vacina BCG, apesar de atingir uma taxa média anual de desperdício em doses semelhante (68, I\%), ocupou a $5^{\text {a }}$ posição em custos de desperdício, com $\mathrm{R} \$ 334.537$ (9,7\%), devido ao menor valor unitário. A vacina com menor custo médio de desperdício foi a dT (R\$33.062), menos de $1 \%$. O que pode justificar esse resultado é o baixo valor médio unitário da dose, em média $R \$ 0,40$, visto que gerou um desperdício de $37,8 \%$ em quantidade de doses.

O custo da vacina depende do formato de apresentação, contudo escolher o melhor tamanho de frasco é uma tarefa complexa (LEE et al., 20I0; DHAMODHARAN; PROANO, 20I2). Os frascos de monodose reduzem o desperdício de vacinas, mas têm preços mais elevados; já as multidoses apresentam maior desperdício, porém valores mais baixos por doses (DRAIN et al., 2003). Este fato foi também confirmado no presente estudo que identificou valores mais baixos para as vacinas de frascos multidoses, com variações de valores por dose da $B C G(R \$ 3,05$ a $R \$ I, 47)$; $d T$ ( $R \$ 0,3$ I a $R \$ 0,48)$; DTP (R\$ 0,60 a $R \$ 0,91)$; FA (R\$ I,78 a $R \$$ 2,58); Hepatite $B(R \$ R \$ 0,9$ a $R \$ 1,52)$. Acrescenta-se que os frascos multidoses, além de oferecerem preços mais baixos por doses, tendem a minimizar os custos de armazenamento e distribuição da cadeia de frio (HEATON et al., 2017). Além disso, têm um menor custo para materiais de embalagem, já que os custos são compartilhados entre muitas doses (DRAIN et al., 2003). Um estudo evidenciou que os custos de fabricação para formatos de vacinas monodose são cerca de 2,5 vezes maiores do que os com frasco de dez doses. No entanto, essa análise não incluiu o preço da vacina (DRAIN et al., 2003).

O presente estudo analisou apenas o preço da vacina, o que possibilitou identificar maiores desperdícios em valores para frascos de monodose, apesar de analisar uma variedade maior de vacinas multidoses. Nesse contexto, pode-se inferir que o uso de frasco monodose, apesar de resultar em menores desperdícios, no geral, incorre em maior custo financeiro pelo valor da dose ser relativamente maior. Entende-se que a escolha de vacinas com doses por frascos depende do contexto de cada país. O custo de frascos multidoses poderão ser relativamente econômico se o desperdício de vacinas não for um problema significativo, a eliminação de resíduos dos serviços de saúde eficaz e a capacidade de transporte e armazenamento apropriada. De outra parte, mesmo que a vacina seja mais cara, se o risco de contaminação é elevado e a demanda de usuários for irregular, os formatos de monodose podem ser os mais favoráveis (LEE et al., 20I0; PARMAR et al., 20I0; PRAVEENA et al., 2015). Corroboramos com os achados de outros estudos que têm como recomendação dispor de apresentações diferentes da mesma vacina. Assim, dependendo da sessão de imunização, poder-se-á escolher a melhor opção de abertura de frasco (PARMAR et al., 20 I0; DRAIN et al., 2003; LEE et al., 20I I).

Reduzir o desperdício, para OMS, tem sido um fator chave na manutenção e na sustentabilidade financeira de programas de imunização (KAMARA et al., 20I2). Economizar custos para um programa de imunização significa melhorar a qualidade e aumentar a eficácia, se o desperdício puder ser reduzido sem afetar a cobertura vacinal (PRAVEENA et al., 20I5).

A literatura nacional e internacional é escassa em relação à análise de desperdício financeiro, especialmente ao considerar a apresentação dos frascos de vacinas. Este trabalho apresentou tanto o custo com o desperdício de algumas vacinas, quanto os valores-limite aceitáveis pela OMS. A redução do desperdício de vacinas poderia facilitar investimentos em novas tecnologias, como a compra de câmaras refrigeradas, equipamentos recomendados para o armazenamento e acondicionamento de vacinas. Ainda, este investimento poderia contribuir para redução de desperdício de vacinas provocado por oscilações de temperatura. Para além do impacto financeiro, poderia melhorar o manejo em situações de eventual escassez. Os resultados subsidiam a importância de consolidar estratégias nesse sentido.

\section{Considerações Finais}

Este trabalho estimou em cerca de $\mathrm{R} \$ 3,5$ milhões anuais os custos do desperdício de 9 vacinas disponíveis no setor público para uma população que representa menos de $2 \%$ do total no território nacional. Assim, uma análise nacional completa evidenciaria valores com desperdícios ainda maiores. Os dados mostram que os custos devidos ao desperdício de vacinas são um elemento crítico para saúde pública, pois cerca da metade 
$(44,7 \%)$ do valor investido nas doses de vacinas tem sido desperdiçado. Ressalta-se que o estudo analisou apenas o preço da vacina, o que possibilitou identificar maiores desperdícios em valores para frascos monodose, apesar de analisar uma variedade maior de vacinas multidoses. Nesse contexto, pode-se inferir que o uso de frasco monodose, apesar de resultar menores desperdícios em doses no geral, incorre em maior custo financeiro, o que implica em significativas perdas de recursos financeiros públicos.

Para optar por uma vacina de apresentação monodose ou multidose, há necessidade de avaliar outras variáveis não consideradas no presente estudo, sugerindo-se estudos posteriores com o custo com transporte, a cadeia de frio, os insumos (seringas e agulhas) e a eliminação de resíduos, entre outros. Ainda, sugerem-se estudos que possam identificar se o desperdício de doses está relacionado com o excesso de aquisição e distribuição de vacinas ou com a redução/ incapacidade de imunização da população.

\section{Referências}

ASSI, Tina-Marie; BROWN, Shawn T; DJIBO, Ali; A NORMAN, Bryan; RAJGOPAL, Jayant; WELLING, Joel s; CHEN, Sheng-I; BAILEY, Rachel R; KONE, Souleymane; KENEA, Hailu. Impact of changing the measles vaccine vial size on Niger's vaccine supply chain: a computational model. Bmc Public Health, [S.L.], v. I I, n. I, p. I-9, 2 jun. 20 I I. Springer Science and Business Media LLC. Disponível em: http://dx.doi.org/I0.I I86/I47I-2458-I I-425. Acesso em: 02 jun. 2020.

BRASIL. Ministério da Saúde. Secretaria de Vigilância em Saúde. Programa Nacional de Imunizações: 30 anos. Brasília: Ministério da Saúde, 2003.

. Ministério da Saúde. Secretaria de Vigilância em Saúde. Departamento de Vigilância Epidemiológica. Programa Nacional de Imunizações (PNI): 40 anos. Brasília: Ministério da Saúde. 2013.

. Ministério da Saúde. Secretaria de Vigilância em Saúde. Departamento de Análise de Situação em Saúde. Saúde Brasil 201 2: uma análise da situação de saúde e dos 40 anos do Programa Nacional de Imunizações. Brasília: Ministério da Saúde, 2013b.536p.

. Ministério da Saúde. Secretaria de Vigilância em Saúde. Departamento de Vigilância das Doenças Transmissíveis. Manual de Normas e Procedimentos para Vacinação. Brasília: Ministério da Saúde, 2014.

DHAMODHARAN, Aswin; PROANO, Ruben A. Determining the optimal vaccine vial size in developing countries: a Monte Carlo simulation approach. Health Care Management Science, [S.L.], v. 15, n. 3, p. I88-196, 19 abr. 2012. Springer Science and Business Media LLC. Disponível em: http://dx.doi.org/I0.1007/s 10729-012-9200-4. Acesso em: 09 ago. 2020.

DIAS, Barbara. Relação entre perdas vacinais e variáveis de infraestrutura em salas de vacinação de uma cidade do Sudeste brasileiro (Dissertação). Rio de Janeiro: Universidade Federal do Rio de Janeiro. 2016.

DRAIN, Paul.; NELSON, Carib.; LLOYD, Johs S. Single-dose versus multi-dose vaccine vials for immunization programmes in developing countries. Bulletin of the World Health Organization: the International Journal of Public Health, 28I (प10) $\square:$ 726-73I. Disponível em: https://apps.who.int/iris/handle/I0665/72063. Acesso em: 09 ago. 2020.

GANDHI, Gian; LYDON, Patrick; CORNEJO, Santiago; BRENZEL, Logan; WROBEL, Sandra; CHANG, Hugh. Projections of costs, financing, and additional resource requirements for low- and lower middle-income country immunization programs over the decade, 20II-2020. Vaccine, [S.L.], v. 3I, p. I37-I48, abr. 20I3. Elsevier BV. Disponível em: http:// dx.doi.org/10.1016/j.vaccine.2013.01.036. Acesso em: 09 ago. 2020.

GAVI ALLIANCE. Report to the GAVI alliance board I8-19 June 2014 - GAVI Alliance immunisation supply chain strategy, 2014. Disponível em:

https://www.gavi.org/sites/default/files/board/minutes/2014//8-june/05\%20-\%20GAVI\%20Alliance\%20immunisation\%20supply\%20chain\%20strategy\%20document.pdf. Acesso em: 13 ago. 2020.

GUICHARD, Stephane; HYMBAUGH, Karen; BURKHOLDER, Brent; DIORDITSA, Serguei; NAVARRO, Christine; AHMED, Selina; RAHMAN, Mohd. Mahbubur. Vaccine wastage in Bangladesh. Vaccine, [S.L.], v. 28, n. 3, p. 858-863, jan. 2010. Elsevier BV. Disponível em: http://dx.doi.org/10.1016/j.vaccine.2009.08.035. Acesso em: 09 ago. 2020. 
HEATON, Alexis; KRUDWIG, Kirstin; LORENSON, Tina; BURGESS, Craig; CUNNINGHAM, Andrew; STEINGLASS, Robert. Doses per vaccine vial container: an understated and underestimated driver of performance that needs more evidence. Vaccine, [S.L.], v. 35, n. 17, p. 2272-2278, abr. 2017. Elsevier BV. Disponível em: http://dx.doi.org/10.1016/j. vaccine.2016.1I.066. Acesso em: 02.ago. 2020.

HOMMA, Akira; MARTINS, Reinaldo de Menezes; LEAL, Maria da Luz Fernandes; FREIRE, Marcos da Silva; COUTO, Artur Roberto. Atualização em vacinas, imunizações e inovação tecnológica. Ciência \& Saúde Coletiva, [S.L.], v. I6, n.

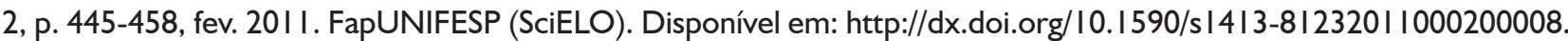
Acesso em: 02. ago. 2020.

LEE, Bruce Y.; NORMAN, Bryan A.; ASSI, Tina-Marie; CHEN, Sheng-I; BAILEY, Rachel R.; RAJGOPAL, Jayant; BROWN, Shawn T.; WIRINGA, Ann E.; BURKE, Donald S.. Single versus multi-dose vaccine vials: an economic computational model. Vaccine, [S.L.], v. 28, n. 32, p. 5292-5300, jul. 2010. Elsevier BV. Disponível em: http://dx.doi.org/10.1016/j. vaccine.2010.05.048. Acesso em: 25. jul. 2020.

LEE, Bruce Y.; ASSI, Tina-Marie; ROOKKAPAN, Korngamon; CONNOR, Diana L.; RAJGOPAL, Jayant; SORNSRIVICHAI, Vorasith; BROWN, Shawn T.; WELLING, Joel S.; NORMAN, Bryan A.; CHEN, Sheng-I. Replacing the measles ten-dose vaccine presentation with the single-dose presentation in Thailand. Vaccine, [S.L.], v. 29, n. 21, p. 38II-3817, maio 20I I. Elsevier BV. Disponível em: http://dx.doi.org/10.1016/j.vaccine.20I I.03.013. Acesso em: 25. jul. 2020.

KAMARA, L.; LYDON, P.; BILOUS, J.; VANDELAER, J.; EGGERS, R.; GACIC-DOBO, M.; MEANEY, W.; OKWO-BELE, J.-M.. Global Immunization Vision and Strategy (GIVS): a mid-term analysis of progress in 50 countries. Health Policy And Planning, [S.L.], v. 28, n. I, p. II-19, 12 mar. 2012. Oxford University Press (OUP). Disponível em: http://dx.doi. org/10.1093/heapol/czs020. Acesso em: 25. jul. 2020.

LYDON, Patrick; GANDHI, Gian; VANDELAER, Jos; OKWO-BELE, Jean-Marie. Health system cost of delivering routine vaccination in low- and lower-middle income countries: what is needed over the next decade?. Bulletin Of The World Health Organization, [S.L.], v. 92, n. 5, p. 382-384, 7 fev. 2014. WHO Press. Disponível em: http://dx.doi. org//0.247I/blt. 13.130146. Acesso em: II. jul. 2020

MAI, Scheila et al. Utilização e perda de doses de vacinas na Região Metropolitana de Porto Alegre, Rio Grande do Sul: um estudo descritivo de 2015-2017*. Epidemiologia e Serviços de Saúde, [S.L.], v. 28, n. 3, p. I-I2, fev. 2020. Disponível em: https://www.scielo.br/scielo.php?pid=S2237-962220 I9000300309\&script=sci_arttext. Acesso em: I3 ago. 2020.

MOFRAD, Maryam H.; MAILLART, Lisa M.; NORMAN, Bryan A.; RAJGOPAL, Jayant. Dynamically optimizing the administration of vaccines from multi-dose vials. lie Transactions, [S.L.], v. 46, n. 7, p. 623-635, 28 mar. 2014. Informa UK Limited. Disponível em: http://dx.doi.org//0. 1080/07408I7x.2013.849834. Acesso em: II. jul. 2020.

MOURA, W.C.B. Avaliação de custos federais do Programa Nacional de Imunizações (Dissertação). Goiás (GO): Universidade Federal de Goiás; 2016.

PARMAR, Divya; BARUWA, Elaine M; ZUBER, Patrick; KONE, Souleymane. Impact of wastage on single and multi-dose vaccine vials: implications for introducing pneumococcal vaccines in developing countries. Human Vaccines, [S.L.], v. 6, n. 3, p. 270-278, mar. 20 10. Informa UK Limited. Disponível em: http://dx.doi.org/I0.4I6I/hv.6.3. 10397. Acesso em: 05. jul. 2020.

PATEL, Prakash B.; RANA, Jayesh J.; JANGID, Sunil G.; BAVARVA, Neha R.; PATEL, Manan J.; BANSAL, Raj Kumar. Vaccine Wastage Assessment After Introduction of Open Vial Policy in Surat Municipal Corporation Area of India. International Journal Of Health Policy And Management, [S.L.], v. 5, n. 4, p. 233-236, 8 dez. 20I5. Maad Rayan Publishing Company. Disponível em: http://dx.doi.org/10.15I7l/ijhpm.2015.208. Acesso em: 05. jul. 2020.

PEREIRA, Diego Daniel dos Santos; NEVES, Eduardo Borba; GEMELLI, Mauro; ULBRICHT, Leandra. Análise da taxa de utilização e perda de vacinas no programa nacional de imunização. Cadernos Saúde Coletiva, [S.L.], v. 2I, n. 4, p. 420-424, 2013. FapUNIFESP (SciELO). Disponível em: http://dx.doi.org/10.1590/s /4I4-462×20130004000 I0. Acesso em: 12. jul. 2020.

PRAVEENA, Daya et al. Vaccine wastage assessment in a primary care setting in rural India. International Journal Of Contemporary Pediatrics, [S.L.], v. 2, n. I, p. 7-I I, 20I5. Medip Academy. Disponível em: http://dx.doi.org/I0.5455/2349329I.ijcp20150202. Acesso em: 12. jul. 2020 
RIO GRANDE DO SUL. Atlas Socioeconômico Rio Grande do Sul. 2018. Disponível em: http://www.atlassocioeconomico.rs.gov.br/regiao-metropolitana-de-porto-alegre-rmpa. Acesso em: I2. jul. 2020.

SETIA, Sabeena; MAINZER, Hugh; WASHINGTON, Michael L; COIL, Gary; SNYDER, Robert; WENIGER, Bruce G. Frequency and causes of vaccine wastage. Vaccine, [S.L.], v. 20, n. 7-8, p. I I48- I I56, jan. 2002. Elsevier BV. Disponível em: http://dx.doi.org/10.1016/s0264-4I0x(0I)00433-9. Acesso em: 05. jul. 2020.

UNICEF. United Nations International Children's Emergency Fund. Vaccine wastage assessment: field assessment and observations from national stores and five selected states in India. [Internet]. 20 I0. Disponível em: http://www.mofa.go.jp/ mofaj/gaiko/oda/seisaku/kanmin/chusho_h24/pdfs/a20-I2.pdf. Acesso em: I5. jun. 2020.

WORLD HEALTH ORGANIZATION. Global Vaccine action plan 20 I I-2020. World Health Organization, 20 I3. Disponível em: https://www.unicef.org/immunization/files/GVAP(I).pdf. Acesso em: I6. jun. 2020

Department of Immunization. Monitoring vaccine wastage at country level. Guidelines for programme managers. Vaccines and Biologicals Family and Community. Health World Organazition. Geneva, 2005.

World Health Assembly endorsed the Global Vaccine Action Plan and World Immunization Week. Geneva: WHO, 20I4. Disponível em: http://www.who.int/immunization/newsroom/global_vaccine_action_plan/en/. Acesso em: 05. jul. 2020. 